\title{
Analysis of laser cut slots on different thickness steel plates
}

Sergiu Constantin Olaru, Margareta Coteaţă, Gheorghe Nagîţ, Adelina Hriţuc, Oana Dodun and Laurenţiu Slătineanu

Sergiu Constantin Olaru. “Gheorghe Asachi” Technical University of Iaşi, Department of Machine Manufacturing Technology,

Blvd. D. Mangeron, 59A, 700023 Iaşi, România

Margareta Coteață. “Gheorghe Asachi” Technical University of Iași, Department of Machine Manufacturing Technology, Blvd. D.

Mangeron, 59A, 700023 Iaşi, România

Corresponding author: mcoteata@tcm.tuiasi.ro

Gheorghe Nagîț. “Gheorghe Asachi” Technical University of Iaşi, Department of Machine Manufacturing Technology, Blvd. D.

Mangeron, 59A, 700023 Iaşi, România

Adelina Hriţuc. “Gheorghe Asachi” Technical University of Iaşi, Department of Machine Manufacturing Technology, Blvd. D.

Mangeron, 59A, 700023 Iaşi, România

Oana Dodun. “Gheorghe Asachi” Technical University of Iaşi, Department of Machine Manufacturing Technology, Blvd. D.

Mangeron, 59A, 700023 Iaşi, România

Laurenţiu Slătineanu. “Gheorghe Asachi” Technical University of Iaşi, Department of Machine Manufacturing Technology, Blvd. D.

Mangeron, 59A, 700023 Iaşi, România

Abstract. One of the processes used to separate parts from plate-type workpiece is laser beam cutting. The evaluation of the quality of the machined surfaces can be performed by taking into account the influence exerted by some input factors in the cutting process on the width of the slot and on the roughness of the surfaces generated by the laser beam cutting process. The paper presents the results of experimental research performed on a steel plate type workpiece. The objective pursued was to reveal the influence exerted by several input factors of the laser beam cutting process on some output parameters of this process. Empirical mathematical models corresponding to the output parameters taken into account were established. It was possible to order the input factors in the process by taking into consideration their weight in the values of the output parameters.

Keywords. Laser Beam Cutting, Experimental Research, Empirical Mathematical Models, Slot Width, Influence Factors

\section{Introduction}

Laser beam cutting is part of the wider group of processing methods so-called nonconventional, along with the methods of processing by electrical discharge, chemical and electrochemical machining, ultrasonic machining, etc. In principle, the laser beam machining is based on the changes generated in the workpiece material at the contact between the surface and a photon beam that has adequate energetic and spatial-temporal characteristics. In machinery manufacturing field, in principle, such cutting processes are used for detaching parts from sheets or strips workpieces. There is obviously the problem of generating slots using the laser beam in individual workpieces, by taking into account the requirements of the mechanical drawings, whose surface quality requirements resulting from machining process must be met.

The problem of generating slots by laser beam cutting has been an objective of theoretical and experimental research in recent decades.

Thus, Grepl et al. analyzed laser cutting of workpieces of various thicknesses [1]. They aimed to determine the machining conditions that ensure the obtaining of good quality machined surfaces, in the case of workpieces made of Haynes 718 alloy, with thicknesses of $2.5 \mathrm{~mm}$ and $3.2 \mathrm{~mm}$, respectively. 
Madić et al. have developed research on the possibilities of using gray relational analysis and a Taguchi's L27 experiment design in the case of an AISI 304 steel workpiece with a thickness of $3 \mathrm{~mm}$ [2]. In another paper, Madić et al. have developed an optimization model with constraints, aiming to maximize the material removal rate in the case of CO2 laser cutting of mild steel [3].

Costa Rodrigues et al. addressed the problem of using an optimal configuration of the laser beam in the case of laser cutting of metal sheets. They have shown that from the energy point of view, it is possible to optimize input factors such as wavelength, polarization and beam shape, so as to ensure good quality surfaces for workpieces made of different materials and with different thicknesses [4].

Wahab and Groninger formulated the problem of optimizing the laser beam cutting parameters by taking into account, as input factors, the cutting speed, gas pressure, focus position, nozzle diameter and nozzle distance [5]. The burr free laser cuts with minimal cut edge surface roughness were the exit parameters taken into account. They established empirical mathematical models that highlight the dependence of burr height and machined surface roughness by the input factors considered.

Pocorni et al. highlighted the influence exerted by cutting speed, laser power and laser wavelength on the values of some quality parameters of the surface obtained by laser beam cutting [6].

Results of an experimental research on the depth of the channels generated by using a $1070 \mathrm{~nm}$ wavelength laser were presented in [7]. An empirical mathematical model was developed to highlight the influence of cutting speed on the depth of the grooves generated by the laser beam.

The objective of this paper was to present the results of research on the influence exerted by the workpiece thickness, but also by other input factors in the laser cutting process, on the width of the slot made in a test sample made of medium carbon steel.

\section{Theoretical approach}

Obtaining the laser beam involves the use of active media that provide conditions for the passage of atomic structures on higher energy levels, and when returning to the initial energy levels to emit a photon beam with convenient spatiotemporal characteristics to materialize a processing. Since the energy density in a cross section through the beam is too small to develop the thermal effect required to cut a metallic workpiece, a lens system is used to allow the beam to focus at a certain distance from the workpiece surface.

At the surface layer of the workpiece, energy is released by the photons and, as a result, a rapid increase in temperature, to values where the workpiece material melts or even vaporizes. Since this melting and vaporization does not allow obtaining a good quality machined surface, along a direction parallel to the axis of the laser beam a gas jet is sent which will determine the rapid removal of molten and vaporized material and the gradual generation of a hole or a slot, if there is a relative movement between the beam and the workpiece. The action of the gas jet contributes to a significant improvement in the quality of the surfaces corresponding to the slot. A schematic graphical representation of the laser beam focusing and its interaction with the workpiece material can be seen in figure 1.

If we accept a conical laser beam with a distribution of energy in the beam in accordance with the law of normal distribution, we will find that the material will melt and vaporize only in those areas of the surface of the workpiece where the temperature generated by the beam will be higher than the melting or vaporizing temperature of the workpiece material. Taking into account the specific shape of the normal distribution of energy density in an axial section through the laser beam (fig. 2), this means that inside a circular area having a diameter smaller than the size of the scattering field of energy density values temperatures will be reached high enough for the workpiece material to 
melt and vaporize. The pressure of the gas jet sent along the beam axis will contribute to the evacuation of the molten or vaporized material from the slit being made. Some of the molten material will solidify in the exit zone of the workpiece, being possible the appearance of a burr. Depending mainly on the workpiece material the assisting gas is chosen; in this case, for cutting slots in a carbon steel plate of different thickness, oxygen was selected. A possible exothermic reaction produced between the workpiece material and the oxygen in the gas jet can contribute to an increase in the material removal rate of the cutting process.

In general, a surface obtained by laser beam cutting has two distinct areas. Thus, there is an area in which we are dealing with ripples parallel to the axis of the laser beam, ripples resulting from pushing the molten material by the gas sent along the same axis. In the case of thicker workpiece, towards the exit zone of the workpiece. These ripples may have a curved direction, directed in the opposite direction to that of the relative movement between the workpiece and the axis of the laser beam. In these zones, the air jet no longer has enough power to evacuate the molten material along the direction defined by the laser beam axis and as a result of the relative movement mentioned above, we will record that curvature of the ripples towards the exit area of the semi-finished product. The zone with curved ripples can have a greater or lesser width, in relation to the gas pressure in the assistance jet and with the thickness of the workpiece

Part of the amount of heat generated by the action of the laser beam on the workpiece will dissipate in the mass of the workpiece immediately adjacent to the zone where the melting and vaporization processes took place. For some materials, the return to ambient temperature can be done at speeds high enough to cause phase changes in the workpiece material. Both these phase changes and the cooling with different speeds of the workpiece material could generate internal stresses which, in the case of thinner zones of the workpiece, could generate deformations capable of further modification of the shape of the cut slot.

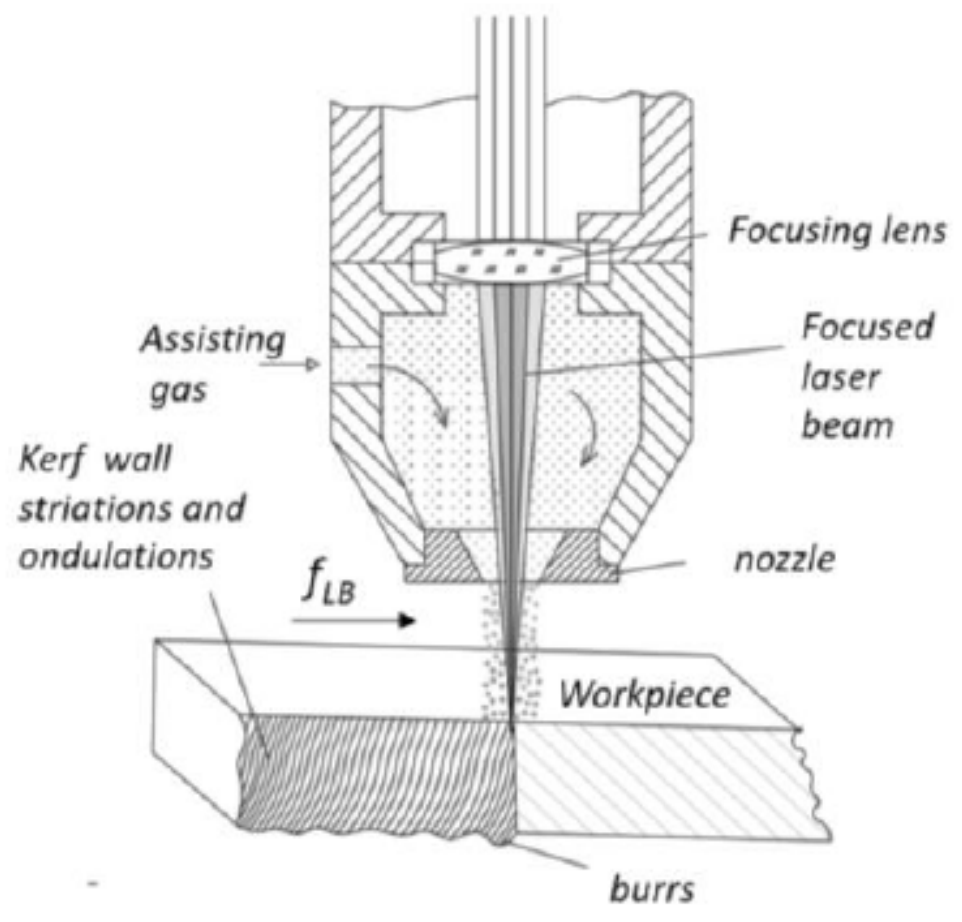

Fig. 1. Directing the laser beam towards the workpiece surface.

The main factors and groups of influencing factors capable of affecting the quality of the slot are the following: 1 . The pressure of the assisting gas sent along the axis of the beam; 2 . The nature of the gas used (nitrogen or oxygen); 
3. The relative displacement speed between the beam axis and the workpiece, along a predetermined trajectory; 4 . The distance between the nozzle and the surface of the workpiece (stand-off distance); 5. Nature and some physical properties of the workpiece material; 6 . Focusing position, i.e., the position of the focal spot in relation to the workpiece upper surface; 7. Thickness of the workpiece.

It can be seen that one of the input factors in the laser beam cutting process that must be taken into account right from the design of the process is the thickness of the workpiece. When the workpiece has a constant thickness along the slot to be made, it is expected that some output parameters of the cutting process (such as slot width and surface roughness) will have similar or close values along the entire length of the slot. In industrial practice, there are situations when slots in workpieces of variable thickness are required. In such a situation, it will be expected that the width of the slot will no longer be constant and the appearance of the processed surface will register significant differences. For a better knowledge of the aspects related to the laser cutting of workpieces with different thicknesses and to verify some of the above-mentioned hypotheses, it became useful to design and materialize an experimental research focused on laser cutting of parts of variable thickness.

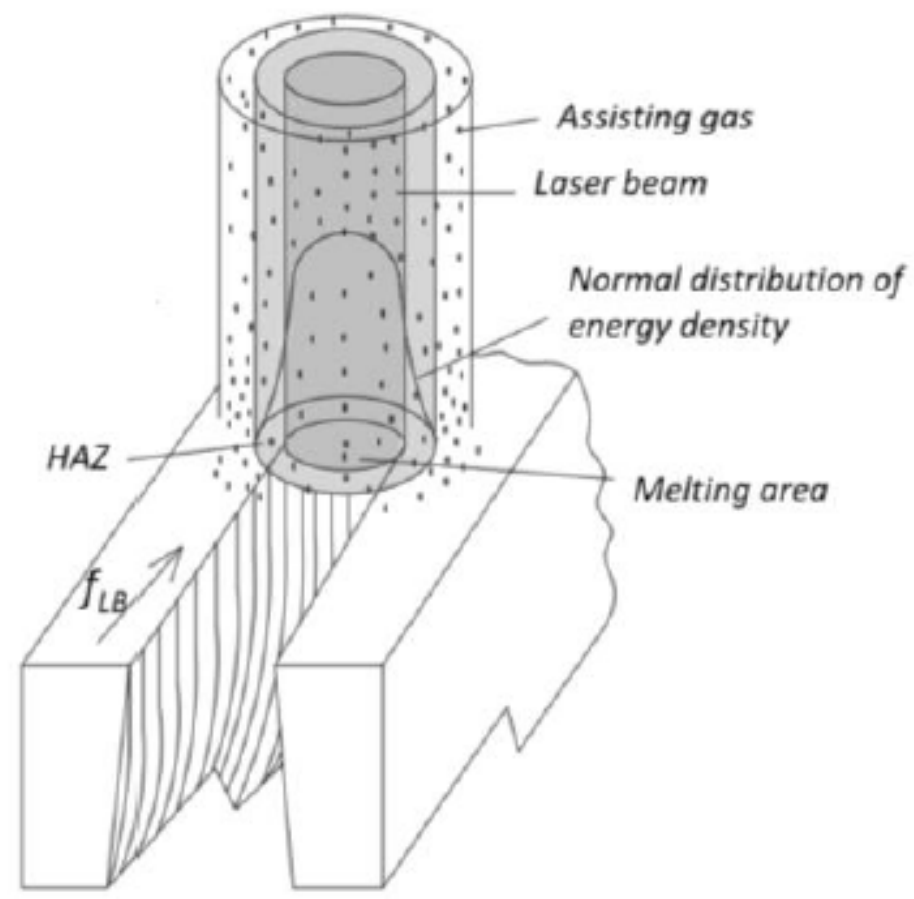

Fig. 2. Development of the laser cutting process for different thickness of the part

\section{Experimental conditions}

The experimental tests were performed on a beam cutting equipment TruLaser 3030 - 3200W, CO2 laser TruFlow. A steel test sample with an average carbon content (C45) was cut. The test piece had zones with 4 different thicknesses $(4,8,12$ and $14 \mathrm{~mm})$. As factors capable of affecting the width $w$ of the slot made by laser beam cutting can be considered the pressure and nature of the gas sent along the laser beam, the energy or power of the laser beam, the distance between the nozzle and the surface of the test piece, focusing distance, thickness of the test sample. In the experimental tests whose results are presented in this paper, taking into account the proper conditions of the tests, the assisting gas pressure $p$, the nozzle stand-off distance $d$, the cutting speed $v$ and respectively the testpiece thickness $t$ of the in the cut area were taken into account as variable input factors in the cutting process. 
Initially, the experimental tests were considered in accordance with the principles of a factorial experiment with 3 independent variables at two levels of variation, starting from the hypothesis that for the investigated domain there will be a monotonous variation of the output parameter (slot width wi in the entry surface and respectively we in the exit surface of the lasercut slot) in relation to the variation of the input factors in the process. Appreciating as being of interest the evaluation of the influence exerted by the thickness $t$ of the test sample on the width of the slot, the four zones of different thicknesses were cut with the same cutting parameters, from a single pass. The values corresponding to other input factors in the laser beam cutting process were kept constant. The nozzle output diameter was $1.7 \mathrm{~mm}$. The average laser power was 3,2 kW and the pulsed laser frequency was of $10 \mathrm{~Hz}$.

The processes of heating and cooling the material as a result of the laser cutting process generate internal stresses capable to generate uncontrolled change in the width of the slot, especially around the pierce point. To avoid such an effect, holes with a diameter of $8 \mathrm{~mm}$ were initially drilled in the test sample, each cutting test being done between two of such holes, the slot being starting and ending in those previously drilled holes (fig. 3 ). In this way, the kerf width was not affected

The upper and lower kerf widths were measured using an optical microscope Mitutoyo MF-A2017B, with the resolution of the length measuring system of $0.5 \mu \mathrm{m}$. For each thickness 3 measurements were taken on each side. Thus, the taper of the slots was observed. For mathematical modelling, the average values of width for each experimental trial were taken into consideration.

The conditions in which the slots were made in the initially prepared test sample and the results of measuring the widths of the slots in the input $\left(w_{i}\right)$ and the exit $\left(w_{e}\right)$ zone of the laser beam from the test sample were presented in table 1.

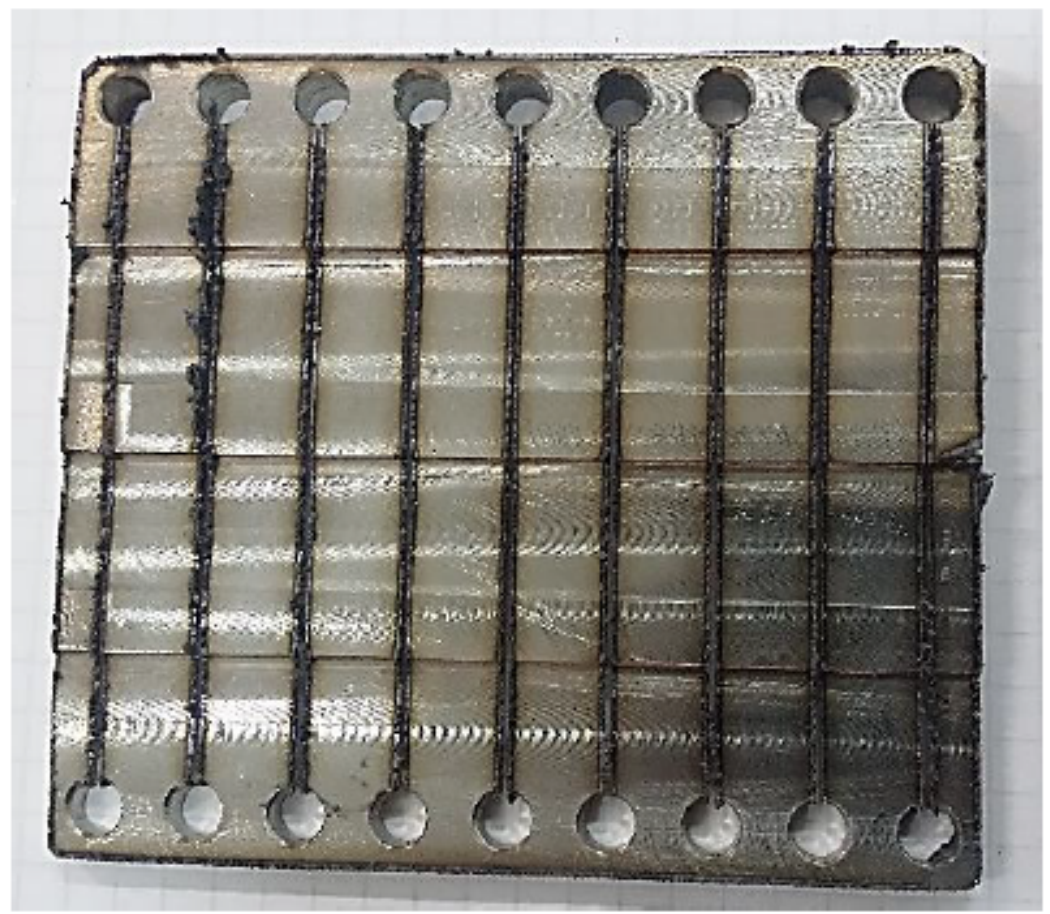

Fig. 3. Test piece in which slots were achieved

Table 1. Experimental conditions and results. 


\begin{tabular}{|c|c|c|c|c|c|c|c|c|c|c|c|c|c|c|}
\hline \multirow{3}{*}{$\begin{array}{l}\text { Exp. } \\
\text { no. }\end{array}$} & \multicolumn{6}{|c|}{ Input factors } & \multicolumn{8}{|c|}{ Output parameter (slot width, $w, \mathrm{~mm}$ ), for distinct thicknesses of the test sample } \\
\hline & \multicolumn{2}{|c|}{$\begin{array}{l}\text { Assisting gas } \\
\text { pressure, } p, \mathrm{MPa}\end{array}$} & \multicolumn{2}{|c|}{$\begin{array}{l}\text { Stand-off } \\
\text { distance } s, \mathrm{~mm}\end{array}$} & \multicolumn{2}{|c|}{$\begin{array}{r}\text { Cutting speed, } v, \\
\mathrm{~m} / \mathrm{min}\end{array}$} & \multicolumn{4}{|c|}{$\begin{array}{l}\text { In the input zone, for the thickness } t \\
\mathrm{~mm} \text { : }\end{array}$} & \multicolumn{4}{|c|}{$\begin{array}{l}\text { In the exit zone, for the thickness } t \text {, } \\
\mathrm{mm} \text { : }\end{array}$} \\
\hline & $\begin{array}{l}\text { Coded } \\
\text { value }\end{array}$ & $\begin{array}{l}\text { Real } \\
\text { value }\end{array}$ & $\begin{array}{l}\text { Coded } \\
\text { value }\end{array}$ & $\begin{array}{l}\text { Real } \\
\text { value }\end{array}$ & $\begin{array}{l}\text { Coded } \\
\text { value }\end{array}$ & $\begin{array}{l}\text { Real } \\
\text { value }\end{array}$ & 14 & 12 & 8 & 4 & 14 & 12 & 8 & 4 \\
\hline 1 & 1 & 0.0686 & 2 & 1.5 & 2 & 0.1 & 0.543 & 0.619 & 0.62 & 0.586 & 0.943 & 0.812 & 0.622 & 0.538 \\
\hline$\underline{2}$ & 1 & 0.0686 & 2 & 1.5 & 1 & 0.08 & 0.548 & 0.558 & 0.553 & 0.563 & 0.858 & 0.625 & 0.519 & 0.518 \\
\hline 3 & 1 & 0.0686 & 1 & 1.15 & 1 & 0.08 & 0.547 & 0.539 & 0.543 & 0.582 & 0.892 & 0.823 & 0.556 & 0.604 \\
\hline 4 & 1 & 0.0686 & 1 & 1.15 & 2 & 0.1 & 0.544 & 0.532 & 0.558 & 0.576 & 0.789 & 0.607 & 0.48 & 0.530 \\
\hline$\underline{5}$ & 2 & 0.098 & 1 & 1.15 & 1 & 0.08 & 0.593 & 0.574 & 0.590 & 0.598 & 1.078 & 0.853 & 0.66 & 0.652 \\
\hline 6 & 2 & 0.098 & 1 & 1.15 & 2 & 0.1 & 0.549 & 0.543 & 0.557 & 0.558 & 1.009 & 0.727 & 0.571 & 0.621 \\
\hline 7 & 2 & 0.098 & 2 & 1.5 & 1 & 0.08 & 0.563 & 0.554 & 0.556 & 0.598 & 1.021 & 0.829 & 0.679 & 0.680 \\
\hline 8 & 2 & 0.098 & 2 & 1.5 & 2 & 0.1 & 0.485 & 0.501 & 0.517 & 0.528 & 0.925 & 0.688 & 0.557 & 0.604 \\
\hline
\end{tabular}

\section{Processing and analyzing the experimental results}

The experimental results were processed using specialized software, based on the use of the least squares method [8]. In principle, the software provides conditions for determining the most appropriate empirical mathematical model among five such models. The so-called Gauss's criterion was used as a criterion for evaluating the adequacy of a certain empirical mathematical model for the results of experimental tests. In this way, it was established that the most appropriate empirical mathematical models for the width of the slots at the entrance $\left(w_{i}\right)$ and at the exit ( $\left.w_{e}\right)$ of the laser beam from the sample are hyperbolic functions, for which the values determined by using the Gauss's criterion are minimal $\left(S G=7.813882 \cdot 10^{-4}\right.$ and respectively $\left.S G=8.751685 \cdot 10^{-4}\right)$. The two hyperbolic functions are the following:

$$
\begin{aligned}
& w_{i}=0.421+\frac{0.002098}{p}+\frac{0.0344}{s}+\frac{0.006008}{v}+\frac{0.125}{t}, \\
& w_{e}=0.932-\frac{0.0205}{p}-\frac{0.0521}{s}+\frac{0.0206}{v}-\frac{1.220}{t} .
\end{aligned}
$$

However, appreciating that some mathematical models of power function type offer a direct image on the intensity of the influence exerted by the input factors on the widths of the slots, two such empirical mathematical models were determined:

$$
\begin{gathered}
w_{i}=0.370 p^{-0.048} s^{-0.0561} v^{-0.128} t^{-0.00160}, \\
w_{e}=0.756 p^{-0.359} s^{-0.0541} v^{-0.322} t^{0.00715}
\end{gathered}
$$

the values of Gauss's criterion being obviously higher in this case $\left(S_{G}=1.698454 \cdot 10^{-2}\right.$ and $\left.S_{G}=2.653599 \cdot 10^{-2}\right)$. By using the empirical mathematical models (3) and (4), the graphical representations from figures 4 and 5 were elaborated. It can notice that an increase in the speed value causes a decrease in the width $w_{e}$ of the slot. This can 
be explained by the fact that by increasing the cutting speed, the laser beam heats a smaller zone of the workpiece material.

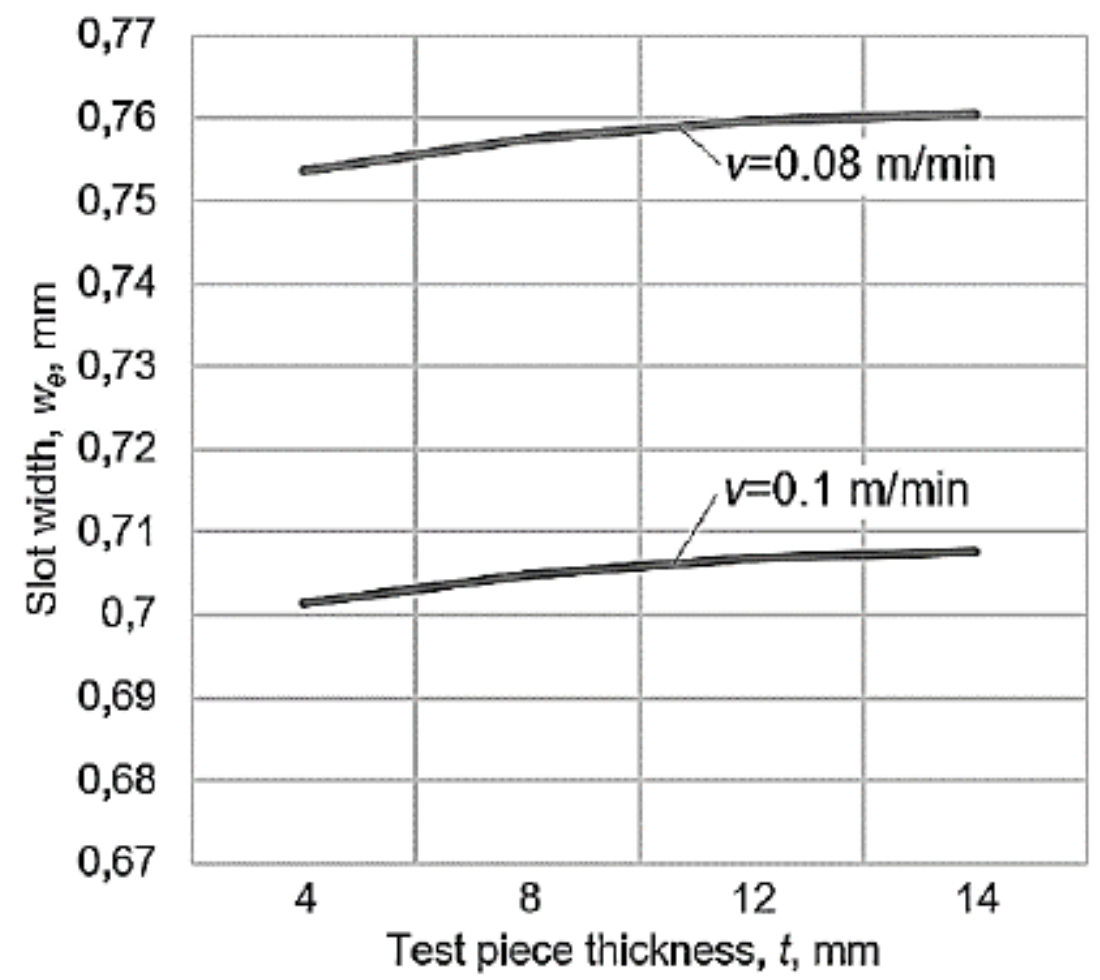

Fig. 4. Effect of the test sample thickness $t$ on the slot width $w_{\mathrm{e}}$ in the exit zone of the laser beam
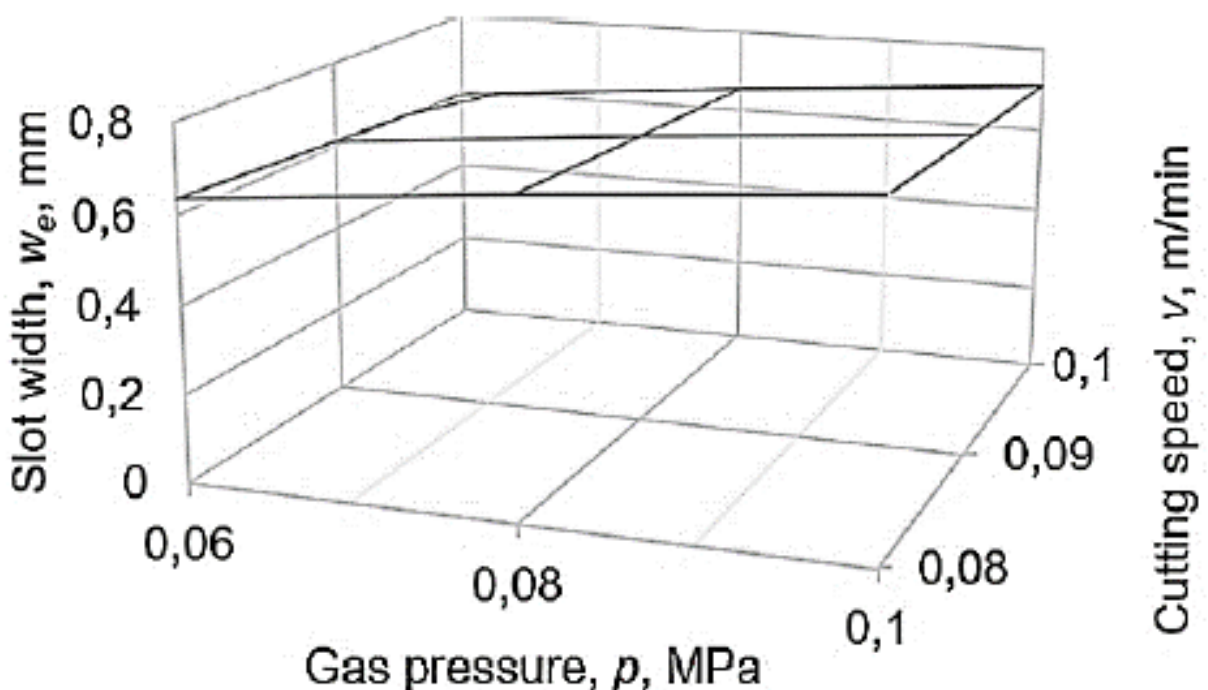

Fig. 5. Effect of the test sample thickness $t$ on the slot width $w_{e}$ in the exit zone of the laser beam

The width $w_{e}$ of the slot in the exit zone is strongly influenced by the pressure $p$ of the assisting gas, an increase in pressure causing an increase in the value we of the slot width, probably due to a faster removal of molten material and 
vaporized by the action of the laser beam.

\section{Conclusions}

The problem of highlighting the influence of different factors on the characteristics of the slots made by laser beam cutting has been an objective of numerous researches. In order to obtain information on the influence exerted by some input factors in the laser beam cutting of a test sample of mild steel, with different thickness experimental tests were performed and the results were mathematically processed. Thus, empirical mathematical models were obtained to highlight the stronger influence of the input factors exerted on the width of the slot in the exit zone of the laser beam in the test sample. It was found that the strongest influence is exerted by the pressure $p$ of the assisting gas and by the cutting speed $v$, because in the mathematical models of type power functions, the highest values of the exponents were attached to these factors. In the future, it is intended to expand the experimental research, by taking into account a greater number of influencing factors and other characteristics of the slots made by laser beam cutting.

\section{Bibliography}

[1] Grepl, M., Pagác, M., Petrú, J. Laser cutting of materials of various thicknesses. Acta Polytechnica, 2012, 52(4), S. $62-67$

[2] Madić, M., Petković, D., Radovanović, M. GRA approach for multi-objective optimization of laser cutting. Scientific Bulletin-University Politehnica of Bucharest, 2014, D, 76 (4), S. 79-90

[3] Madić, M., Mladenović, S., Gostimirović, M., Radovanović, M., Janković, P. Laser cutting optimization model with constraints: Maximization of material removal rate in CO2 laser cutting of mild steel. Proceedings of the Institution of Mechanical Engineers, Part B: Journal of Engineering Manufacture, 2020, 234, 10

[4] Costa Rodrigues, G., Vorkov, V., Duflou, J.R. Optimal laser beam configuration for laser cutting of metals sheets. Procedia CIRP 2018, 74, S. 714-718

[5] Wahab, H., Gröninger, J. Optimization of laser cutting quality with design of experiments. Cutting mild steel with high brightness diode lasers. Laser Technik Journal, 2014, 11(5), S. 27-31

[6] Pocorni J.K., Powell, J., Ilar, T., Schwarz, A., Kaplan, A.F.H. Measuring the state-of-the-art in laser cut quality. 14th Nordic Laser Materials Processing (NOLAMP) Conference, Gothenburg, Sweden, 2013, S. 101-108

[7] Slătineanu, L., Coteață, M., Dodun, O., Beşliu, I. Obtaining slots and channels by using a 1070 nm wavelength laser. Procedia CIRP, 2013, 6, S. 480-486

[8] Crețu, G. Fundamentals of experimental research. Laboratory handbook (in Romanian), Gheorghe Asachi Technical University Iași, Romania, 1992.

PDF automatically generated on 2021-05-20 01:33:57

Article url: https://popups.uliege.be/esaform21/index.php?id=2681

published by ULiège Library in Open Access under the terms and conditions of the CC-BY License (https://creativecommons.org/licenses/by/4.0) 